\title{
Materials and Structures
}

\section{Use of a reference limestone fine aggregate to study the fresh and hard behavior of mortar made with recycled fine aggregate \\ --Manuscript Draft--}

Manuscript Number:

Full Title:

Article Type:

Keywords:

Corresponding Author:
MAAS-D-18-01401R2

Use of a reference limestone fine aggregate to study the fresh and hard behavior of mortar made with recycled fine aggregate

\section{Original Research}

Recycled fine aggregate; model natural fine aggregate; water absorption; saturation; effective water

Mohamed EIKarim Bouarroudj, PHD student

IMT Lille Douai

Douai, FRANCE

\section{Corresponding Author Secondary}

Information:

Corresponding Author's Institution:

IMT Lille Douai

\section{Corresponding Author's Secondary} Institution:

First Author:

First Author Secondary Information:

Order of Authors:

Order of Authors Secondary Information:

Funding Information:

\section{Abstract:}

Response to Reviewers:
Mohamed ElKarim Bouarroudj, PHD student

Mohamed EIKarim Bouarroudj, PHD student

Sébastien Remond, Professor

Frédéric Michel, Laboratory Head

Zengfeng Zhao, Senior Researcher

David Bulteel, Professor

Luc Courard, Professor

Interreg France-Wallonie-Vlaanderen

2014-2020

Not applicable

(VALDEM convention $n^{\circ} 1.1 .57$ )

Recycled fine concrete aggregates (RFA) are not enough used in the construction sector, mainly because of their high water absorption capacity. These fine particles are composed of crushed natural aggregate and adherent hardened cement paste. The main goal of this research is to compare the behaviors of mortars made either with RFA or with a model limestone fine natural aggregate (LFA). The LFA is prepared in order to obtain physical properties as close as possible to those of the RFA. A specific characterisation is carried out to compare the density, water absorption, morphology of grains, size distribution and packing density of both aggregates. Mortars are then manufactured with same composition and same volume of LFA and RFA. Different states of moisture of the RFA are studied. The fresh behaviour of the mortar made with saturated RFA is very close to that of the mortar made with LFA which confirms that the latter is a good reference compared to the RFA. Comparison of fresh behaviours of mortars made with RFA of different state of moisture to that of mortar made with saturated sand allows then to determine the water absorbed in the different moisture conditions. Afterwards, a mechanical study is realised, taking into consideration the exact quantity of absorbed water of the RFA in dry or saturated conditions. Knowing the exact effective water value allows us to study both the strength of mortar made with RFA, the strength of the matrix and the adherence between the fine aggregate and the paste.

The authors declare that they have no conflict of interest. 


\section{Additional Information:}

Question

Response

Provide the total number of words in the

7355

manuscript (excluding figure caption and table caption)?

Provide total number of FIGURES? 7

Provide total number of TABLES? 


\section{Use of a reference limestone fine aggregate to study \\ 2 the fresh and hard behavior of mortar made with \\ 3 recycled fine aggregate}

4 Mohamed ElKarim Bouarroudj ${ }^{\mathrm{a}, b^{*}}$, Sébastien Remond ${ }^{\mathrm{a}}$, Frédéric Michel ${ }^{\mathrm{b}}$, Zengfeng Zhao ${ }^{\mathrm{b}}$, $5 \quad$ David Bulteel ${ }^{\mathrm{a}}$, Luc Courard ${ }^{\mathrm{b}}$

6 aIMT Lille Douai, Univ. Lille, EA4515-LGCgE-Laboratoire de Génie Civil et 7 géoEnvironnement, Département Génie Civil and Environnemental, F-59000 Lille, France

8 buniversity of Liège, Urban and Environment Research Unit, ArGEnCo Department, GeMMe 9 Building Materials, Liège, Belgium

\section{Abstract}

11 Recycled fine concrete aggregates (RFA) are not enough used in the construction sector, mainly because of their 12 high water absorption capacity. These fine particles are composed of crushed natural aggregate and adherent 13 hardened cement paste. The main goal of this research is to compare the behaviors of mortars made either with 14 RFA or with a model limestone fine natural aggregate (LFA). The LFA is prepared in order to obtain physical 15 properties as close as possible to those of the RFA. A specific characterisation is carried out to compare the density, water absorption, morphology of grains, size distribution and packing density of both aggregates. Mortars are then manufactured with same composition and same volume of LFA and RFA. Different states of moisture of the RFA are studied. The fresh behaviour of the mortar made with saturated RFA is very close to that of the mortar made with LFA which confirms that the latter is a good reference compared to the RFA. Comparison of fresh behaviours of mortars made with RFA of different state of moisture to that of mortar made with saturated sand allows then to determine the water absorbed in the different moisture conditions. Afterwards, a mechanical study is realised, taking into consideration the exact quantity of absorbed water of the RFA in dry or saturated conditions. Knowing the exact effective water value allows us to study both the strength of mortar made with RFA, the strength of the matrix and the adherence between the fine aggregate and the paste.

Keywords: Recycled fine aggregate- model natural fine aggregate- water absorptionsaturation- effective water

\section{Introduction}

Large quantities of construction and demolition wastes (CDW) are produced each year. For example, the annual production of CDW is around 260 million tons in France [1] and 15 million tons in Belgium [2]. Amongst these wastes, Recycled Concrete Aggregates (RCA) can be considered as inert, and could be used as an alternative source of aggregates for the production 
of new concrete. So far, only a small fraction of these RCA is used as aggregate in concrete 33 production.

34 RCA are composed of a mix of natural aggregates and hardened cement paste. Comparing to natural aggregates, RCA possess a high water absorption coefficient, (between 4 and 12\%) and a lower density (between 2.1 and $2.5 \mathrm{~g} / \mathrm{cm}^{3}$ ) [3-5] The cement paste increases the porosity of the material. Cement paste content of RCA is larger in recycled fine aggregate (RFA) than in coarse recycled aggregate[6,7]: this is why RFA represents the most difficult part to valorize. Several research works have been carried out in order to use RFA as aggregate to manufacture mortars or concrete[8,9], as a mineral addition in cementitious materials [10] or as raw material in cement manufacturing [11].

RCA are often incorporated into concrete or mortar as substitution of natural aggregates. The influence of RCA substitution rate on the properties of concrete is controversial. Braga et al. [12] studied the incorporation of fine recycled concrete aggregates in mortars with replacement ratios of 5, 10 and 15\%. An improvement of rheological and mechanical behaviors was observed when the RCA was incorporated. Neno et al.[13] proposed a substitution of natural fine aggregate (NFA) by RFA in different percentage ratio, and found that to have the same fresh and hardened behavior of mortar, the replacement ratio in mortar composition is limited to $20 \%$ by volume of replacement. Vegas et al. [14] studied the performances of masonry mortars made with fine recycled concrete aggregates; a substitution rate of 25, 50, 75 and 100\% of the NFA by RFA was investigated. In this study, the quantity of water was adjusted in order to work with the same consistency. The mechanical results showed that the incorporation of up to $25 \%$ of recycled aggregate didn't affect the properties of hardened masonry mortars. Pedro et al. [15] studied the simultaneous incorporation of fine and coarse recycled aggregates in concrete. The results show that it is possible to achieve a comparable structural element with recycled material, to those performed with natural one. Carro-Lopez et al. [16] showed that substitution of up to $20 \%$ of natural aggregate (NA) by RCA decreased the fresh properties of mortar and concrete. Omary et al. [17] and Fan et al. [18] found that using recycled aggregate decreased the mechanical properties of mortar and concrete. But Hu et al. showed the opposite [19]. Vinay Kumar et al. [20] performed an experimental study on the use of coarse and fine aggregates to design a self-compacting concrete (SCC) : $20 \%$ of natural coarse and fine aggregates were replaced by recycled aggregates. No significant difference was observed on the rheological behavior, but an improvement in the mechanical behavior was observed. In similar studies, Omrane et al. [21] and Kou et al. [22] found that the recycled aggregate substitution should be limited to $50 \%$ in order to fulfil all recommendations of SCC. Carro- 
Lôpez et al.[23] studied the rheology of SCC with RFA. NFA was replaced by $20 \%, 50 \%$, and $100 \%$ by RFA. The natural and recycled fine aggregate were sieved and recomposed in order to have a similar particle size distribution. The mixing water was adjusted by adding extra water corresponding to water absorbed after 10 minutes. The results showed a decrease in fresh and hardened properties of concrete for $50 \%$ and $100 \%$ of replacement of natural fine aggregate by recycled one.

The literature review shows contradictory results concerning detrimental (or beneficial) effect of NA substitution by RCA. This variability might first be due to the nature of the used aggregates (both natural and recycled) coming from different sources. But the comparison itself between mortars or concretes manufactured with NA and with RCA might be questioned. In order to find out whether NA substitution by RCA decreases (or increases) concrete properties, the composition parameters of the two concretes have to be as close as possible. In particular, efficient water to cement ratio, volume of aggregates, and physical characteristics of the granular skeleton (particle size distribution, particle's morphology ...) should be similar. Several research works have already compared the behavior of mortars containing NFA to mortars produced with RFA[23]. But to our knowledge, comparison of two mortars possessing very similar mixture proportions and material characteristics has not been carried out yet. In this study, the fresh and hardened properties of mortars manufactured with RFA are compared to those of mortars of identical compositions with NFA presenting very similar physical characteristics to those of RFA. The main objective is to study, when the composition parameters of mortars are almost identical, what is the effect of a total substitution of NFA by RFA.

\section{Methodology}

Ideally, the simplest way to study the effect of substitution of NFA by RFA in mortars would be to replace a given volume of NFA by the same volume of RFA, keeping the workability of the mortars constant. Then, mechanical properties of the two mortars could be compared and the effect of this substitution (negative or even positive) could be derived. However, replacing NFA by RFA generally leads to changes both in the fresh and hardened properties of mortars. In this study, we need therefore to first define a model NFA, starting from a given RFA, that would lead to the same properties in fresh state for two mortars and where the only difference would be the nature of the fine particles (either RFA or NFA). 
97 For this purpose, the rheological behavior has to be defined and can be described approximately by the Krieger \& Dougherty model [24] (Eq. 1).

$$
\eta_{\mathrm{c}}(\phi)=\eta_{\mathrm{c}}(0)\left(1-\frac{\phi}{\phi_{m}}\right)^{-[\eta] \phi_{\mathrm{m}}}
$$

where : $\eta_{c}(\phi)$ is the viscosity of the suspension, $\eta_{c}(0)$ is the viscosity of the interstitial fluid, $\phi$ is the solid volume fraction of particles in suspension, $\phi_{\mathrm{m}}$ is the maximum packing fraction and $[\eta]$ is the intrinsic viscosity of particles (depending on their shape).

Several studies [25-27] have proven that the previous parameters are of first order for the control of mortars and concrete rheological behavior.

If one wants the two previous mortars (with NFA or RFA) to possess the same rheological behaviour, the four parameters of the Krieger \& Dougherty model should be the same. That is to say:

- The viscosity of the suspending fluid (the cement paste) should be the same in both mortars. This implies that the two mortars contain the same effective water to cement ratio $\left(\mathrm{W}_{\text {eff }} / \mathrm{C}\right)$. As RFA generally possess a high water absorption coefficient, the only way to precisely control the effective water is to use pre-saturated RFA, so that water movements between cement paste and RFA can be prevented;

- The solid volume fraction of aggregates in the two mortars should be identical. This necessitates using the same envelop volume of particles (i.e. the volume of solid particle plus internal particle porosity should be constant);

- The maximum packing fraction should be constant, which at least implies that particle size distributions and particle's morphologies would be very similar;

- The intrinsic viscosity of particles should also be the same. Intrinsic viscosity for real fine aggregate particles is difficult to define; however, this constraint would be fulfilled if particles of the two fine aggregates had approximately the same particles geometry and same particle surface.

Based on the previous elements, the RFA and NFA used in this study have been defined as follows:

- The RFA has been produced from the crushing of a laboratory concrete of known composition.

- The NFA has been produced by crushing the natural coarse aggregate used for the manufacture of the parent concrete, with the same procedure and same crusher as for the RFA; 
The NFA has then been cut in seven different size fractions $(2 / 4 \mathrm{~mm}, 1 / 2 \mathrm{~mm}$, $0.5 / 1 \mathrm{~mm}, \quad 0.25 / 0.5 \mathrm{~mm}, \quad 0.125 / 0.25 \mathrm{~mm}, \quad 0.063 / 0.125 \mathrm{~mm}$, and $<0.063 \mathrm{~mm}$ ) and recomposed to have the same particle size distribution (PSD) as the RFA.

132 Fig. 1 shows the used procedure. The physical properties of RFA and NFA will be determined and compared in order to verify if the fabrication procedure allows to produce two similar aggregates (section 3). Then, mortars of identical composition will be produced with the two sands and their rheological behavior will be compared in order to verify if the NFA can be considered as a good model for the RFA (section 4). Finally, the compressive strengths of mortars will be determined in order to assess the real effect of the substitution of NFA by RFA on the mechanical behavior of mortars (section 5).

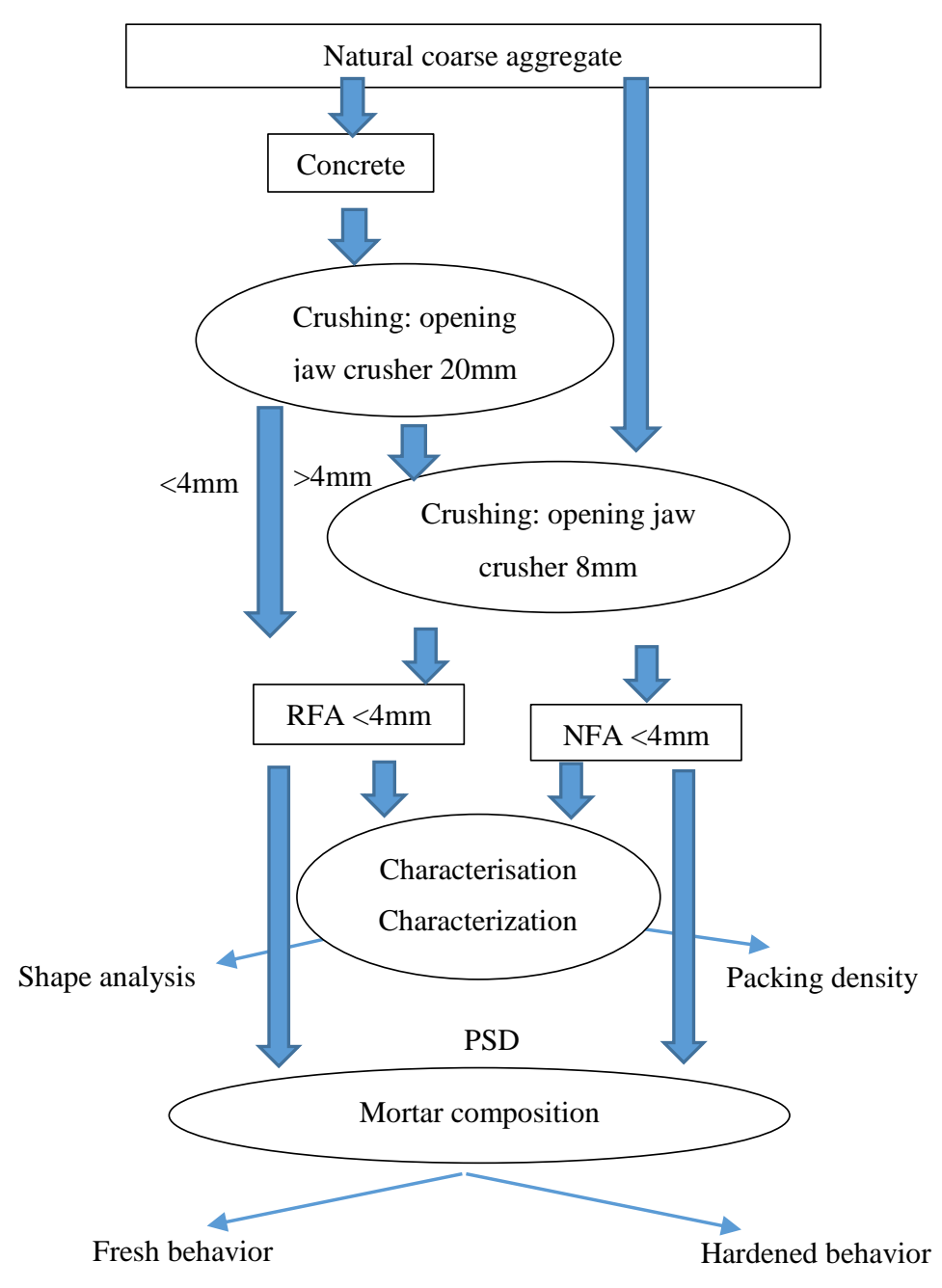

Fig. 1 Followed Methodology - preparation of aggregates - RFA = Recycled Fine Aggregates - NFA = Natural 160 Fine Aggregates 


\section{Characterisation of fine aggregate}

\subsection{Materials}

A CEM I 52.5N cement from CBR Belgium, complying with standard EN 197-1 is used. The density measured with Helium pycnometer is $3.11 \mathrm{~g} / \mathrm{cm}^{3}$ and the specific surface area measured according to the standard EN $196-3$ is $3800 \mathrm{~cm}^{2} / \mathrm{g}$. Limestone aggregates $2 / 7 \mathrm{~mm}, 7 / 14 \mathrm{~mm}$, and $14 / 20 \mathrm{~mm}$ are provided by Carmeuse in Belgium. The natural sand $0 / 4 \mathrm{~mm}$ is provided by LOVEMAT in Belgium. These materials are used for manufacturing a laboratory concrete which is then crushed for the production of RFA. Table 1 shows the concrete composition. The latter has been designed in order to obtain a consistency class S3 and strength class C30/37. The concrete slump measured according to NF EN 12350-2 is $129 \mathrm{~mm}$, and its 28 days compressive strength measured on cubic specimen $(15 \times 15 \times 15 \mathrm{~cm})$ is $41 \mathrm{MPa}$.

173 Table 1 Concrete composition used to prepare the RFA

\begin{tabular}{ccccccc}
\hline $\begin{array}{c}\text { CEM I } \\
(\mathbf{k g})\end{array}$ & $\begin{array}{c}\text { Water } \\
(\mathbf{k g})\end{array}$ & $\begin{array}{c}\text { Aggregate 2/7 } \\
(\mathbf{k g})\end{array}$ & $\begin{array}{c}\text { Aggregate } \\
\mathbf{7 / 1 4}(\mathbf{k g})\end{array}$ & $\begin{array}{c}\text { Aggregate } \\
\mathbf{1 4 / 2 0}(\mathbf{k g})\end{array}$ & $\begin{array}{c}\text { Fine Aggregate } \\
(\mathbf{0} / \mathbf{4})(\mathbf{k g})\end{array}$ & $\begin{array}{c}\text { Superplasticizer } \\
(\boldsymbol{\%})\end{array}$ \\
\hline 350 & 175 & 216 & 658 & 436 & 612 & 0.4 \\
\hline
\end{tabular}

The concrete is crushed with a jaw crusher after 90 days curing to insure a high level of hydration; only the fraction smaller than $4 \mathrm{~mm}$ is recovered. The crushing procedure is performed in two steps: the first step uses an opening jaw crusher of $20 \mathrm{~mm}$, and the fraction less than $4 \mathrm{~mm}$ is recovered. The fraction above $4 \mathrm{~mm}$ is crushed a second time with an opening jaw crusher of $8 \mathrm{~mm}$. After crushing, the $0 / 4 \mathrm{~mm}$ fraction is carefully homogenized.

A limestone aggregate $20 / 32 \mathrm{~mm}$ from the same quarry than the aggregate use for manufacturing the concrete (Carmeuse in Belgium) is crushed with an opening jaw crusher of $8 \mathrm{~mm}$. After that, 182 the limestone fine aggregate (LFA) is recomposed in order to have the same size distribution 183 than the RFA.

\section{$184 \quad 3.2$ Shape analyses}

185 The shape analyses are carried out with $2 \mathrm{~d}$ images $[28,29]$ and the measurement is performed 186 with the fraction larger than $250 \mu \mathrm{m}$ for a mass of sample between 250 and $300 \mathrm{~g}$. This test is 187 performed in order to identify the shape of particles, and to know if the preparation procedure presented in Fig. 1 allows to have a similar shape between RFA and LFA. 
189 The sample is gradually laid on a cover belt. Thanks to a camera and a source of light, each particle is individually evaluated and parameters are calculated. In this work, between 100,000 and 200,000 particles are analyzed. Afterwards, length and width of each particle are recorded. The morphology is expressed in terms of elongation. The elongation parameter is computed with (Eq. 2). Fig. 2 shows the results obtained for RFA and LFA: no significant differences are observed for the different size fractions.

$$
\text { Elongation }=1-(\text { width } / \text { length })
$$

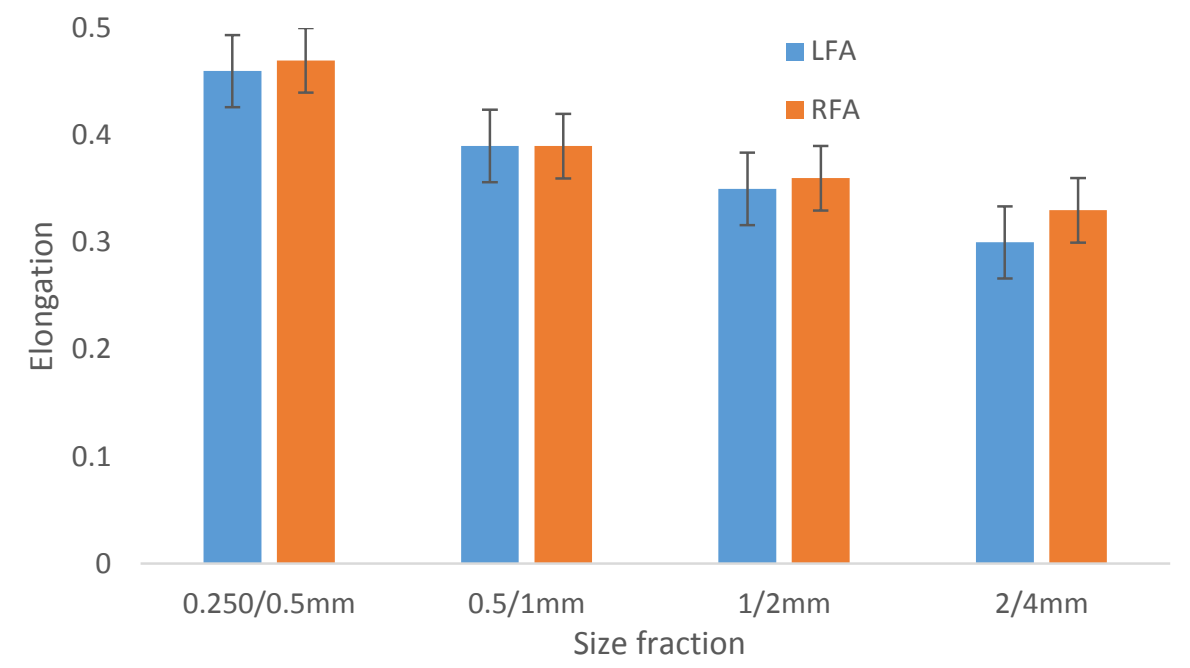

Fig. 2 Elongations for the different particle sizes of RFA and LFA

\subsection{Water absorption and density}

199 Three methods are investigated for the measurement of water absorption coefficient of RFA: EN 1097-6 [30], IFSTTAR method Nº78 [31] and extrapolation method [6].

Using the standard EN 1097-6 or IFSTTAR method, water absorption is determined by measuring the quantity of water present in the aggregate at saturated surface dry state (SSD).

203 Firstly, the aggregates are saturated with a certain amount of water for 24 hours. In EN 1097204 6, in order to achieve SSD, the sample is exposed to a warm air flow for evaporating the water 205 present at the surface of particles. The SSD state is identified using a slump test. A cone is filled 206 in one time and compacted with 25 pestles shots. The SSD state is determined according to the 207 shape obtained after lifting the cone. In IFSTTAR method, for achieving SSD state, the sample 208 is dried progressively by using different colored absorbing papers until there is no more trace 209 of water. 
In both methods, the mass of sample at SSD state is recorded $\left(\mathrm{M}_{\mathrm{SSD}}\right)$. Then the sample is dried in an oven at $105^{\circ} \mathrm{C}$ until constant mass ( $\mathrm{M}_{\text {dried }}$ ). The water absorption (WA) is computed with (Eq. 3).

$$
\mathrm{WA}=\left(\mathrm{M}_{\mathrm{SSD}}-\mathrm{M}_{\text {dried }}\right) / \mathrm{M}_{\text {dried }} \ldots \ldots \ldots \ldots \text { (3) }
$$

Le et al.[32] have shown that the EN 1067-6 method underestimates the water absorption of the finer granular fractions, whereas the IFSTTAR method overestimates it. The extrapolation method developed by Zhao et al. [6] is therefore also used in this research. This method is based on the relationship between the water absorption and the cement paste content. For determining the water absorption, the sample is divided in different size classes and the adherent cement paste content is measured for each size class. (Eq. 4) shows that there is a linear relationship between the adherent cement paste content and the water absorption. Zhao showed that the measurement of water absorption coefficient is possible only for coarser classes with standard EN 1097-6 or IFSTTAR method (down to $0.5 \mathrm{~mm}$ ) [32]; the water absorption of the finer fraction is then computed by extrapolation with (Eq.4). Knowing the proportion of each size fraction of RFA, the water absorption of the whole $0 / 4$ fraction can be determined.

$$
\mathrm{WA}_{\mathrm{RFA}}=\mathrm{WAP} \mathrm{X}_{\mathrm{P}}+\mathrm{WA} \mathrm{A}_{\mathrm{NA}}\left(1-\mathrm{X}_{\mathrm{p}}\right)
$$

WARFA: water absorption coefficient of a given size class of RFA

$\mathrm{WA}_{\mathrm{p}}$ : water absorption coefficient of adherent cement paste

WANA: water absorption coefficient of natural aggregate in RFA

$\mathrm{X}_{\mathrm{p}}$ : adherent cement paste content of a given class of RFA

230 In this study, the RFA is sorted into 6 size fractions: $(<0.063 \mathrm{~mm}, 0.063 / 0.125 \mathrm{~mm}$, $2310.125 / 0.5 \mathrm{~mm}, 0.5 / 1 \mathrm{~mm}, 1 / 2 \mathrm{~mm}$, and $2 / 4 \mathrm{~mm})$. The water absorption coefficients of the size 232 fractions larger than $0.5 \mathrm{~mm}$ are determined with IFSTTAR method: by extrapolation, the total water absorption for RFA is then determined. Le et al. [32] showed that using EN 1097-6 or IFSTTAR method lead to very close WA results for the fraction between $0.5 / 4 \mathrm{~mm}$.

In the extrapolation method, the adherent cement paste content can be estimated either by soluble fraction in salicylic acid (SFSA) or mass loss (ML) between $105^{\circ} \mathrm{C}$ and $475^{\circ} \mathrm{C}$ both methods are investigated here.

The SFSA is determined by immersing $0.5 \mathrm{~g}$ of dry representative sample into a solution of salicylic acid and methanol (14g of salicylic acid and $80 \mathrm{ml}$ of methanol) during 1 hour to dissolve the soluble phases of the cement paste. After that, the solution is filtered to obtain the 241 solid residue. This method is carried out on 2 samples of each granular fraction. 
The mass loss between $105^{\circ} \mathrm{C}$ and $475^{\circ} \mathrm{C}$ is determined by (1) storing $10 \mathrm{~g}$ of representative samples for 24 hours in the oven at $105^{\circ} \mathrm{C}$ and weighing the sample $\left(\mathrm{M}_{105^{\circ}} \mathrm{C}\right)$ (2) putting the sample in the oven at $475^{\circ} \mathrm{C}$ for 24 hours and weighing the sample $\left(\mathrm{M}_{475^{\circ}} \mathrm{c}\right)$. The mass loss is computed with the (Eq. 5).

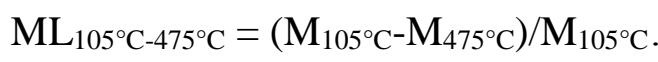

In this research, the water absorption is determined under the three following different absorption conditions.

- IM 24 hours: total immersion into water for 24 hours (porosity and real density are computed with this saturation procedure corresponding to EN 1097-6);

- 7 days WA+5\%: conservation in sealed bottle for 7 days with a quantity of water equal to $\mathrm{WA}+5 \%$ of the mass of the sample

- 24 hours WA+5\%: conservation in sealed bottle for 24 hours with a quantity of water equal to WA $+5 \%$ of the mass of the sample;

Le et al. [32] showed that conservation of RFA for 7 days in a sealed bottle with a quantity of water equal to $\mathrm{WA}+5 \%$ allowed to saturate the RFA.

Fig. 3 and Fig. 4 show the variation of water absorption for each size fraction and for the different moisture conditions, with the extrapolation method, using respectively the soluble fraction in salicylic acid (SFSA) and mass loss (ML). The results show a linear relation between the water absorption and the mass loss (ML) or the (SFSA). For the different fractions, there is non-significant difference between the samples immersed in water and the one saturated with $\mathrm{WA}+5 \%$ of the mass of the sample for 7 days. It can also be seen that the sample saturated with $\mathrm{WA}+5 \%$ for 24 hours has a lower water absorption comparing to the two others. It also means that, if the capillary rise is not complete after 24 hours, the saturation is completed after 7 days; this result is similar to that presented by Le et al.[32].

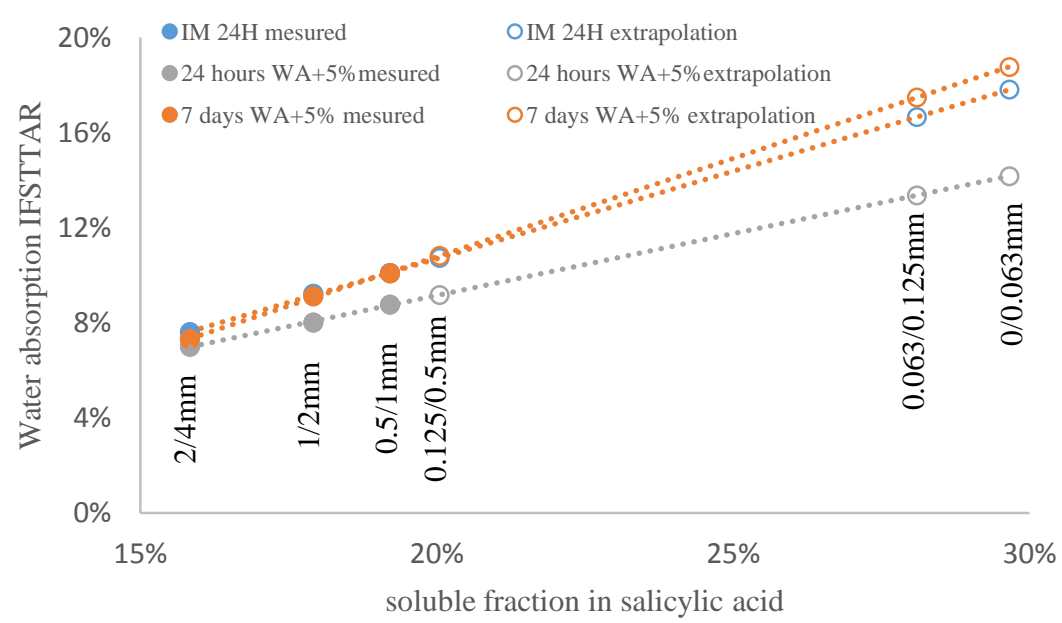


Fig. 3 Extrapolation method with the soluble fraction in salicylic acid (SFSA)

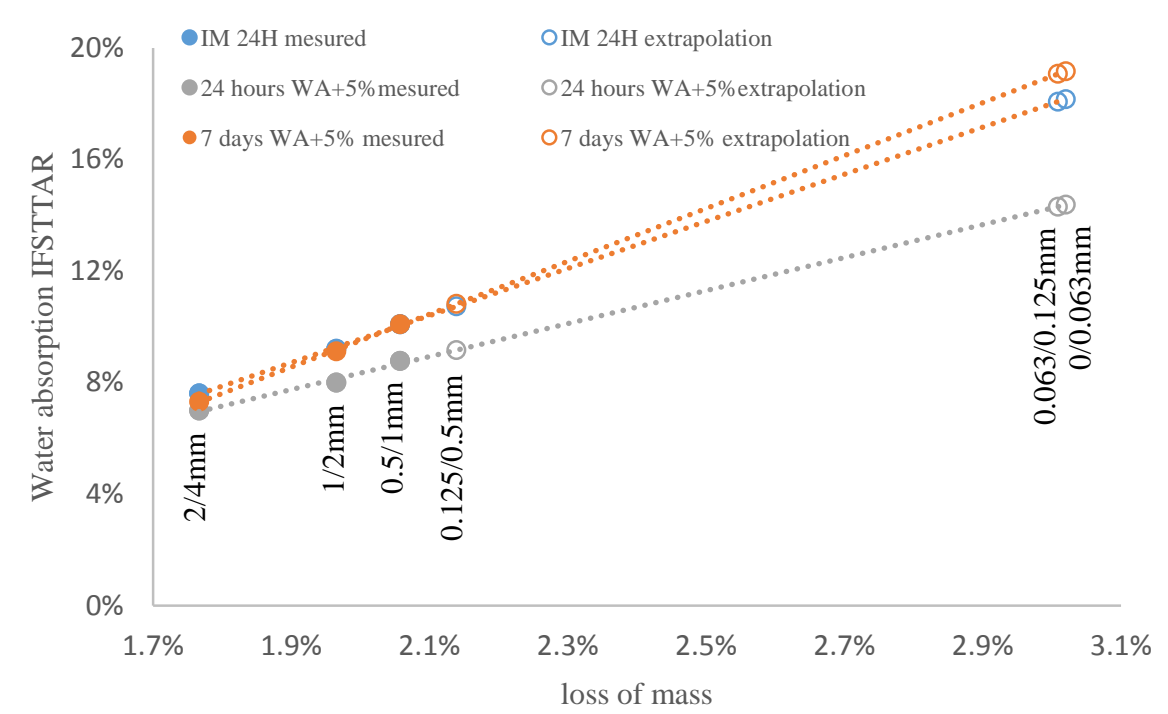

Fig. 4 Extrapolation method with the mass loss (ML)

Table 2 shows the details of the different water absorption measurements. For the different moisture conditions, the water absorption coefficient is very close when using ML and SFSA for the extrapolation method.

Table 2 Water absorption for the different moisture condition of RFA

\begin{tabular}{cccc}
\hline & IM 24 HOURS & 24 HOURS WA+5\% & 7 DAYS WA+5\% \\
\hline WA EN 1097-6 (\%) & 7.5 & 7.4 & 9.0 \\
\hline WA IFSTTAR (\%) & 10.8 & 10.4 & 9.6 \\
\hline WA IFSTTAR extrapolation & 9.7 & 8.4 & 9.7 \\
SFSA (\%) & & & \\
WA IFSTTAR extrapolation & 9.8 & 8.5 & \\
\hline
\end{tabular}

Bordy et al.[33] showed that the residual anhydrous crushed paste, when in contact with water, can harden and agglomerate. To verify if agglomeration of finer particles happens after 7 days of conservation, the particle size distribution is measured after drying the material at $60^{\circ} \mathrm{C}$ until constant mass. The PSD has changed a lot which can be due to the agglomeration of RFA presaturated for 7 days. This can certainly be attributed to anhydrous phases of RFA reacting with water and changing the granular skeleton. Such a change in particle size distribution can affect the workability of the mortar manufactured with this mode of saturation. 
The WA of LFA is measured according to standard EN 1097-6. The value of absolute density $\left(\rho_{\mathrm{ab}}\right)$ is determined according to the standard EN 1097-6; the porosity $(\mathrm{P})$ and real density $(\rho)$ are obtained with (Eq. 6) and (Eq. 7).

$$
\begin{gathered}
\mathrm{P}=\frac{W_{a b s}}{W_{a b s}+\frac{1}{\rho_{a b}}} \ldots \ldots \ldots \ldots \ldots \ldots \ldots \ldots \ldots \ldots \ldots \ldots \ldots \ldots \ldots \ldots \ldots \ldots \ldots \ldots \ldots \ldots \ldots \ldots \ldots \ldots \ldots \ldots \ldots \\
\rho
\end{gathered}
$$

The Apparent density and the water absorption measured for the samples immersed for $24 \mathrm{~h}$ into water for LFA are $2.69 \mathrm{~g} / \mathrm{cm}^{3}$ and $1 \%$ respectively. For the RFA, the extrapolation method is used to compute the porosity and real density, the apparent density and real density for RFA are respectively 2.4 and $1.94 \mathrm{~g} / \mathrm{cm}^{3}$.

\subsection{Packing density}

The packing density has an impact on the rheological behavior of mortar or concrete [24]. In this research, same PSD and very close particle shape are obtained for RFA and LFA. These two fine aggregates should therefore present similar packing densities.

The LCPC protocol [25] is carried out for the measurement of packing density $\left(\phi_{\mathrm{m}}\right)$. This test is realized by placing a dry sample of $7 \mathrm{~kg}$ in a cylinder of $160 \mathrm{~mm}$ of diameter and a height of $600 \mathrm{~mm}$ fixed to a vibrating table. A flat piston of $20 \mathrm{~kg}$ is placed on top of the cylinder to exert a pressure of $10 \mathrm{KPa}$. The cylinder is vibrated for 1 minute, and the apparent volume after vibration is measured. $\phi_{\mathrm{m}}$ is computed with (Eq. 8) where $\rho_{\mathrm{app}}$ is the apparent density measured after the test and $\rho$ is the real density presented in $\S 3.3$.

Packing density of RFA and LFA are $86 \%$ and $84 \%$, respectively. In order to verify that the measurement did not generate any fine particle, the PSD is also measured after the test.

$$
\phi_{\mathrm{m}}=\left(\rho_{\mathrm{app}}\right) /(\rho)
$$

The PSD analyses performed before and after the packing density test show a significant increase in the quantity of fine particles. This is the reason why the value obtained with this method is not taken into consideration.

308 The generation of fine particles is certainly due to the use of a weight of $20 \mathrm{~kg}$ and a vibration 309 of 1 minute. The same protocol is therefore reproduced without the weight of $20 \mathrm{~kg}$. The packing 310 density of RFA and LFA is in this case $80 \%$ and $75 \%$, respectively. PSD analyses are carried 311 out after the measurement and show no generation of fine particles in this case. 
312 Given the procedure used for the production of RFA and LFA, the physical envelop

\section{3}

Table 3 Mortar compositions for the investigation of fresh behavior

\begin{tabular}{lccccccc}
\hline & $\begin{array}{c}\text { Cement } \\
(\mathbf{g})\end{array}$ & $\begin{array}{c}\text { Limestone } \\
\text { filler (g) }\end{array}$ & $\begin{array}{c}\text { Fine } \\
\text { Aggregate (g) }\end{array}$ & $\begin{array}{c}\text { Effective } \\
\text { water (g) }\end{array}$ & WA (g) & Weff/C & Weff/P \\
\hline Reference & 1344 & 895 & 3968 & 1209 & 39 & 0.9 & 0.54 \\
\hline Recycled & 1344 & 895 & 2942.9 & 1209 & 288 & 0.9 & 0.54 \\
\hline
\end{tabular}

In order to justify whether the difference in packing densities showed in part 3 is significant for the fresh behavior of mortars, the Krieger-Dougherty model is used (Eq. 1). Mehdipour and Khayat [34] consider that the $\phi_{\mathrm{m}}$ parameter for the application of Krieger-Dougherty model is the packing densities obtained when using LCPC measurement. $\phi_{\mathrm{m}}$ value for RFA and LFA are given in part 3.4.

Table 4 presents the relative viscosities obtained with the Krieger-Dougherty model based on the characterisation results and mortar compositions. As observed in Table 3, the solid volume fraction of aggregates in the mortar $(\phi)$ is identical for RFA and LFA, but the packing densities $\left(\phi_{\mathrm{m}}\right)$ present a difference of $5 \%$. A small difference is obtained for the relative viscosities between mortars of LFA and RFA.

Due to the small differences between aggregate properties, and to the small difference obtained for the predicted relative viscosities, the rheology of mortars made with saturated RFA and LFA should be very close. 
Table 4 Comparison between the relative viscosities of RFA and LFA

\begin{tabular}{cccc}
\hline & $\boldsymbol{\phi}$ & $\boldsymbol{\Phi}_{\mathbf{m}}$ & $\boldsymbol{\eta}_{\mathbf{c}}(\boldsymbol{\phi}) / \boldsymbol{\eta}_{\mathbf{c}}(\mathbf{0})$ \\
\hline LFA & $43 \%$ & $75 \%$ & 5.032 \\
\hline RFA & $43 \%$ & $80 \%$ & 4.798
\end{tabular}

\subsection{Pre-saturation conditions and mixing procedure}

Different saturation states of RFA are studied. RFA is first dried at $60^{\circ} \mathrm{C}$ until a constant mass. The mortars are then produced with 5 different pre-saturation conditions of RFA in order to study the water movement between the paste and RFA:

- Dry RFA: first mixed with the powders and then the total water is added;

- Paste + dry RFA: preparation of the paste with water first then add the dry RFA;

- 5 min WA+5\%: add to RFA a quantity of water equal to WA+5\% for 5 minutes[35];

- 24 hours WA+5\% : add to RFA a quantity of water equal to WA+5\% for 24 hours;

- 24 hours IM: add to RFA all the quantity of water for preparing the mortar (in order to assure that all the particles are immersed in water).

The saturation is achieved by storing the fine aggregates with the amount of water needed in watertight containers. The containers are conserved in air-conditioned room at $20^{\circ} \mathrm{C}$.

The LFA is used after a saturation of $\mathrm{WA}+5 \%$ for 5 minutes, according to the protocol presented by Schwartzentruber and Catherine [35].

Complete immersion of RFA into water for 24 hours (24 hours IM) should allow for the saturation of RFA and should prevent water movements in mortar. Other saturation modes should lead to larger workabilities for mortars [32]. In order to quantify the effective water and estimate the water absorption for a given moisture condition, quantities of water equal to 20 , 40 and $60 \%$ of the water absorption of RFA, respectively, are added to the effective water in mortars manufactured with saturated sand (24 hours IM). The same quantity of water was used for mortars with LFA. Fig. 5 shows the procedure used to produce the different mortars. 


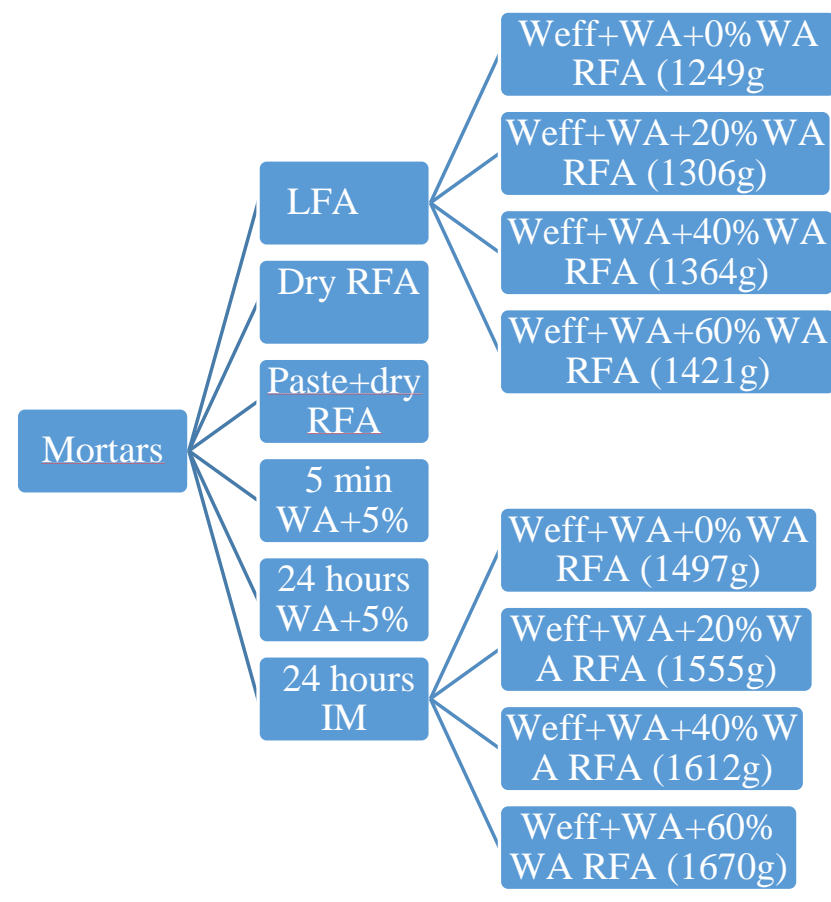

Fig. 5 Mortars manufactured to study the water movements between RFA and cement paste. The total water added in the mixes is put between brackets.

Cement, limestone powder, RFA, LFA and water are first stored at $20^{\circ} \mathrm{C}$. Depending on the way of saturation of RFA, cement, limestone powder, fine aggregate, and the total water are mixed at a low speed for 90 seconds; 60 seconds of manual mixing are then following. Finally, 90 seconds of mixing at high speed are performed.

When dry RFA is used, the cement, limestone filler and water are added first and mixed for 60 seconds; the dry RFA is then added and another 60 seconds of mixing are performed. 60 seconds of manual mixing are then following. Finally, 90 seconds of mixing a high speed are performed.

\section{$372 \quad 4.3$ Fresh state properties}

373 For each mortar, the apparent density, slump (H) and slump flow (D) are measured. All the tests 374 are performed three times to assure a good repeatability. The slump and slump flow tests are performed with a mini cone whose upper diameter is $70 \mathrm{~mm}$, lower diameter is $100 \mathrm{~mm}$, and height is $60 \mathrm{~mm}$.

In order to determine the yield stress, Roussel's model is used [36]. To apply this model, the slump radius should be larger than the height of the slump $(\mathrm{D} / 2>\mathrm{H})$. The empirical yield stress may then be computed with (Eq. 9).

- $\quad \rho$ : fresh apparent density of mortar $\left(\mathrm{g} / \mathrm{cm}^{3}\right)$ 
- g: gravity $9.8 \mathrm{~m} / \mathrm{s}^{2}$

- $\quad \Omega$ : volume of the mini cone $\left(\mathrm{mm}^{3}\right)$

- $\quad \mathrm{R}$ : radius of the slump (mm)

\subsection{Rheological behavior}

Table 5 shows the apparent density, slump flow and yield stress calculated with Roussel's model. The mortar manufactured with immersed RFA has the closest results to the one manufactured with LFA. The mortar made with RFA saturated with WA+5\% for 24 hours presents better workability than the one performed with immersed RFA. This result confirms that conservation of RFA with WA $+5 \%$ for 24 hours does not allow reaching complete saturation. Referring to the water absorption (Table 2), a difference of $1.3 \%$ is observed between this saturation condition and total immersion in water of RFA: this may explain the improvement of workability observed for the mortar made with RFA with WA+5\% saturated for 24 hours.

Using RFA in dry condition or saturated with WA $+5 \%$ for 5 minutes gives similar behaviors in the fresh state and leads to the highest workability. This result is due to the incomplete absorption of water by dry fine aggregate (or fine aggregate saturated only for 5 minutes) which leads to maximal amount of effective water for fluidizing the mixture. Adding the RFA in dry condition in the paste gives a lower workability than in the two previous conditions.

Table 5 Fresh properties of the mortars

\begin{tabular}{cccc}
\hline & Density $\left(\mathbf{g} / \mathbf{c m}^{\mathbf{3}}\right)$ & Slump Flow $(\mathbf{m m})$ & Yield stress Roussel's model (Pa) \\
\hline LFA & 2.22 & 163 & 124 \\
\hline Dry RFA & 1.88 & 210 & 32.1 \\
\hline Paste +dry RFA & 1.88 & 193 & 47.7 \\
\hline $\mathbf{5}$ min WA+5\% & 1.87 & 205 & 34.1 \\
\hline $\mathbf{2 4}$ hours + WA+5\% & 1.92 & 172 & 79.3 \\
\hline $\mathbf{2 4}$ hours IM & 1.95 & 158 & 130 \\
\hline
\end{tabular}

Fig. 6 shows the variations of slump flow and yield stress of mortars made with LFA and RFA after total immersion in water as a function of the efficient water to powder ratio. It is observed that there is only a small difference (in yield stress and slump flow) between the mortars made with LFA and RFA immersed in water. 


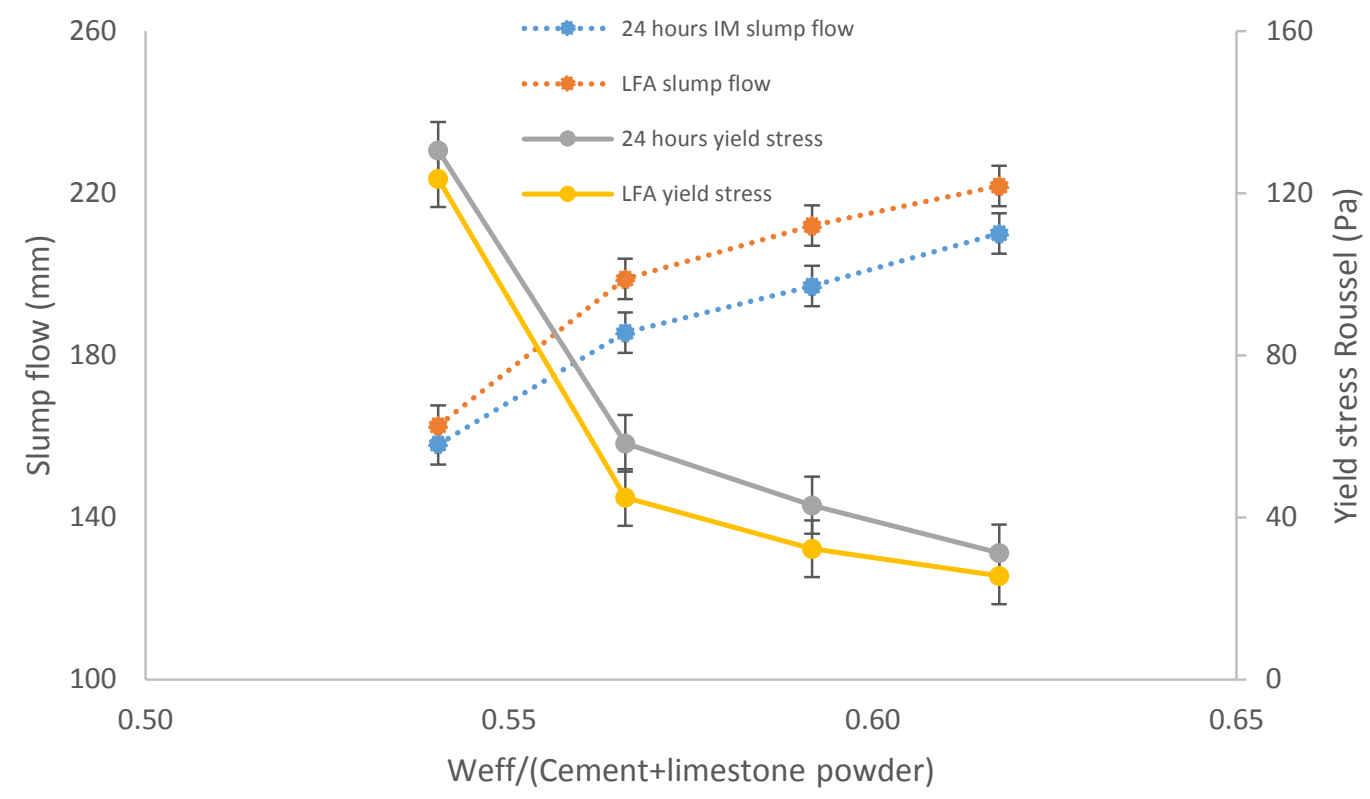

Fig. 6 Workability of the mortar manufactured with LFA and RFA immersed in water for 24 hours

Fig. 7 shows the yield stress measured with Roussel's model as a function of the water in excess. Adding 20,40, and $60 \%$ of the RFA water absorption quantity allows computing the percentage of excess water for the different moisture conditions.

412 Previous studies show an exponential decrease of yield stress when the W/C increases in the case of pure cement paste [37,38]. In our work, using a parabolic equation gives better regression than using an exponential trend, which may be due to the fact that mortar is used and not a pure paste. Yield stresses obtained with Roussel's model presented in Table 5 are used in order to compute the water in excess and then the water absorption for each moisture condition[39].

418 The mortar made with RFA saturated with WA+5\% for 24 hours presents a yield stress of 79Pa. 419 Based on this result, the water absorption can be computed with the parabolic relation and corresponds to $8.33 \%$. The water absorption presented in Table 2, with a saturation state of $\mathrm{WA}+5 \%$ for 24 hours, shows a similar value which means that the water absorption kinetics are identical for the two tests. This result validates the fact that the rheological study can be used for computing the water absorbed in the different states of moisture.

424 The use of RFA in dry conditions or after 5 minutes of saturation gives close yield stresses. 425 Based on these values, the water absorption calculated is $5.3 \%$ and $5.7 \%$, respectively. The saturation degree which is the ratio of the water absorbed and the standard water absorption 427 (WA, Table 2) is around $54 \%$.

428 Adding dry RFA to the paste leads to a smaller yield stress; the water absorbed calculated for 429 this condition is $6.81 \%$, which means that the saturation degree of RFA is $70 \%$. In this 
condition, RFA absorbs more water than when it is added with the powder and water. Maimouni et al. [39] showed that, after 5 minutes of mixing, the degree of saturation of dry RFA in cement paste with W/C ratio equal to 0.5 is around $70 \%$ : this result is similar to the result obtained for the mortar made with RFA in the same condition.

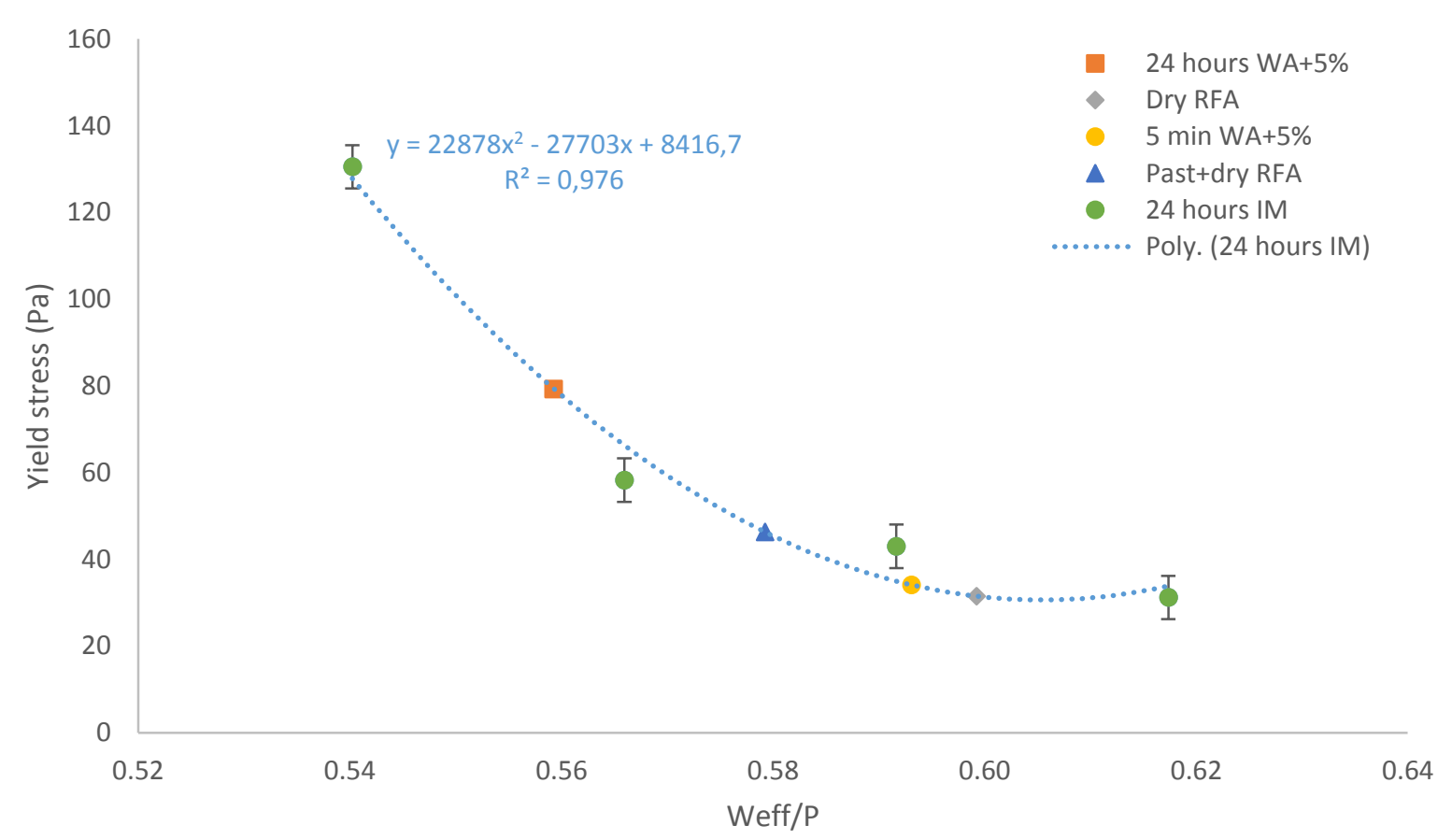

435 Fig. 7 Measure of yield stress as a function of Weff/P ratio for the different mortars with RFA in different 436 moisture conditions

\section{5. Mechanical behavior of mortars}

438 Zhao et al. [40] showed that the state of moisture influences the interface between the new and old cement paste, the difference having an impact on the mechanical strength. These authors found that using RFA in dry condition leads to better mechanical properties. However, in a similar research Le et al. [41] found no significant difference between the compressive strengths of mortars made either with dry or saturated RFA. In order to better understand the influence of moisture state of RFA on the compressive strength of mortars, different specimen are manufactured with dry or saturated RFA and compared with mortar made with model LFA. Compressive strengths are measured on mortars with RFA and LFA. Prismatic specimens (40mm X 40mm X 160mm) are prepared according to standard EN 196-1. The flexural and compressive strengths are measured according to standard EN 196-1.

Table 6 shows the mortar compositions. For the different mixes, the effective water content - + $0 \%, 40 \%$ and $60 \%$ of the water absorption after a total immersion into water of RFA - is 
considered. The fresh behavior study made in section 4 allows knowing the water absorbed for the different moisture conditions. In order to assure the same efficient water for the different mortars, the water absorbed by RFA in dry or in total immersion is taken into consideration in the water mixes. The water absorption considered in the mortar composition with RFA used in dry condition is equal to $5.3 \%$, and equal to $9.8 \%$ for immersed RFA as shown in Table 6.

Table 6 Mortar compositions for the evaluation of mechanical performances

\begin{tabular}{ccccccc}
\hline & $\begin{array}{c}\text { Cement } \\
(\mathbf{g})\end{array}$ & $\begin{array}{c}\text { Limestone filler } \\
(\mathbf{g})\end{array}$ & $\begin{array}{c}\text { Fine } \\
\text { aggregate } \\
(\mathbf{g})\end{array}$ & $\begin{array}{c}\text { Effective } \\
\text { water }(\mathbf{g})\end{array}$ & $\begin{array}{c}\text { Absorbed } \\
\text { water }\end{array}$ & $\begin{array}{c}\text { Weff/ } \\
\text { (Cement+limestone } \\
\text { filler) }\end{array}$ \\
\hline LFA 0\% & 1344 & 895 & 3968 & 1209 & 39.7 & 0.54 \\
\hline LFA 40\% & 1344 & 895 & 3968 & 1325 & 39.7 & 0.59 \\
\hline LFA 60\% & 1344 & 895 & 3968 & 1382 & 39.7 & 0.62 \\
\hline DRY RFA 0\% & 1344 & 895 & 2943 & 1209 & 156 & 0.54 \\
\hline DRY RFA 40\% & 1344 & 895 & 2943 & 1325 & 156 & 0.59 \\
\hline DRY RFA 60\% & 1344 & 895 & 2943 & 1382 & 156 & 0.62 \\
\hline 24 hours IM 0\% & 1344 & 895 & 2943 & 1209 & 288 & 0.54 \\
\hline 24 hours IM 40\% & 1344 & 895 & 2943 & 1325 & 288 & 0.59 \\
\hline 24 hours IM 60\% & 1344 & 895 & 2943 & 1382 & 288 & 0.62 \\
\hline
\end{tabular}

According to De Larrard [42], the compressive strength of concrete or mortars is related to the compressive strength of cement matrix and is given by (Eq. 10).

$$
\mathrm{R}_{\mathrm{c}}=\frac{p \times R_{c m}}{q \times R_{c m}+1}
$$

$\mathrm{R}_{\mathrm{cm}}$ : compressive strength of the cement matrix

$\mathrm{R}_{\mathrm{c}}$ : compressive strength of mortar

p: adhesion quality between the aggregate and cement matrix

p/q: characterize the ceiling effect which the limiting effect of the aggregate on the mechanical behavior of the mortar or concrete.

The compressive strength of the cement matrix is computed by (Eq. 11).

$$
\mathrm{R}_{\mathrm{cm}}=13.4 \times \mathrm{R}_{\mathrm{c} 28} \times\left(\frac{V p}{V p+V w+V a}\right)^{2.85} \times \mathrm{MPT}^{-0.13}
$$

$\mathrm{R}_{\mathrm{c} 28}$ : represents the compressive strength of the standard mortar made with cement and limestone powder with the same proportion as showed in Table 3 at 28 days.

$\mathrm{Vp}, \mathrm{Vw}, \mathrm{Va}$ : represent the volume of powder, water and air. The volume of air is measured with air content CONTROLS/1L. 
MPT: the maximum paste thickness between two close aggregates computed from (Eq. 12).

$$
\begin{aligned}
& \qquad M P T=D_{\max } \times\left(\sqrt[3]{\frac{g *}{g}}-1\right) \ldots \ldots \ldots \ldots . .(12) \\
& D_{\text {max }} \text { : maximal size of aggregate } \\
& \text { g: the aggregate volume for a unit volume of mortar. } \\
& \mathrm{g}^{*} \text { : the granular packing density, computed with eq (Eq. 13). } \\
& \qquad \mathrm{g}^{*}=1-0.45 \times\left(\frac{d_{\min }}{d_{\max }}\right)^{0.19} \ldots \ldots \ldots \ldots . .(13)
\end{aligned}
$$

$\mathrm{d}_{\min }$ : diameter corresponding to $10 \%$ passing.

$\mathrm{d}_{\max }$ : diameter corresponding to $90 \%$ passing.

According to De Larrard [42], for high matrix strengths, the mortar strength is equal to $R_{c}=p / q$; but for low matrix strengths, it is equal to $R_{c}=p \times R_{c m}$. In this work, a high W/P ratio is used to allow for a total immersion of RFA in water during the saturation phase. This high W/P ratio leads to low matrix strengths. This is consequently mainly the adherent parameter (p) and its effect on the mechanical resistance which are of interest here.

Table 7 presents the compressive strength of the different mortars. Mortars with LFA showed a higher compressive strength than those made with RFA, whatever their saturation state. Also, the compressive strength of the mortar made with dry RFA is larger than that of the mortar made with saturated RFA. The air content was higher for RFA mortars than LFA mortars. Moreover, the air content is larger in the mortar made with dry RFA than in the mortar with saturated RFA. The larger air contents of mortars made with RFA in comparison to those made with LFA can certainly be attributed to differences in surface rugosity of particles, probably larger for RFA than for LFA. The larger air content of mortars made with dry RFA in comparison to saturated RFA is certainly due to the air present in the non-saturated particles. In section 4, a difference of $4.5 \%$ of WA is observed between the saturated and dry RFA. This difference in water absorption could increase the air content in mortars made with dry RFA by $3.5 \%$. According to the air contents presented in Table 7, a difference of $2.5 \%$ is obtained between the mortar made with dry RFA and saturated RFA. This result confirms that the increase in air content for mortars made with dry RFA is due to the air still present in the pores which are not filed with water. So, for the application of the De Larrard model [42], the same air content for the matrix of the mortar made with saturated RFA is going to be used for the mortar made with dry RFA. 
Table 7 Compressive strength of mortars, and details for the investigation of the "ceiling effect"

503

\begin{tabular}{|c|c|c|c|c|c|c|c|c|c|}
\hline \multirow[b]{2}{*}{ Weff/P } & \multicolumn{3}{|c|}{ LFA } & \multicolumn{3}{|c|}{ RFA dry } & \multicolumn{3}{|c|}{ IM 24H RFA } \\
\hline & 0.54 & 0.59 & 0.62 & 0.54 & 0.59 & 0.62 & 0.54 & 0.59 & 0.62 \\
\hline $\begin{array}{c}\text { Vair/Vtotal } \\
\text { in mortar } \\
(\%)\end{array}$ & 1 & 1 & 1 & 7 & 7 & 7 & 4.5 & 4.5 & 4.5 \\
\hline $\begin{array}{l}\text { Vair in paste } \\
\text { /Vtotal (\%) }\end{array}$ & 1 & 1 & 1 & 4.5 & 4.5 & 4.5 & 4.5 & 4.5 & 4.5 \\
\hline $\mathbf{g}$ & 0.43 & 0.42 & 0.41 & 0.41 & 0.39 & 0.39 & 0.42 & 0.40 & 0.40 \\
\hline$g^{*}$ & 0.76 & 0.76 & 0.76 & 0.76 & 0.76 & 0.76 & 0.76 & 0.76 & 0.76 \\
\hline MPT & 0.68 & 0.73 & 0.75 & 0.76 & 0.80 & 0.83 & 0.73 & 0.77 & 0.79 \\
\hline $\mathbf{R}_{\mathrm{c} 28}(\mathrm{MPa})$ & 25.03 & 25.03 & 25.03 & 25.03 & 25.03 & 25.03 & 25.03 & 25.03 & 25.03 \\
\hline $\mathbf{R}_{\mathrm{cm}}(\mathbf{M P a})$ & 22.34 & 18.88 & 17.42 & 18.73 & 15.90 & 14.69 & 18.73 & 15.90 & 14.69 \\
\hline $\mathbf{R}_{\mathbf{c}}(\mathbf{M P a})$ & 26.99 & 24.42 & 20.29 & 17.37 & 15.55 & 14.89 & 14.35 & 13.03 & 10.34 \\
\hline $\mathbf{p}$ & & 1.222 & & & 0.948 & & & 0.766 & \\
\hline
\end{tabular}

As explained above, the De Larrard model is presented only with the p parameter because of the low cement matrix. The adhesion between LFA and paste is better than the one between RFA and paste. Using RFA in dry condition allows for a better adhesion than when saturated. This result is in accordance with the study of Zhao et al. [40]

Higher compressive strengths obtained for mortars with LFA than for mortars with RFA can therefore be attributed to two parameters: a higher air content in the paste of mortars made with RFA comparing to the one made with LFA and a better adhesion between the LFA and new paste.

\section{Conclusions}

As this is very difficult to study the real effect of substitution, a natural by a recycled fine aggregate, an original method has been proposed for preparing a natural model aggregates and comparing it with recycled one. Specific physical characterisation carried out on both aggregates shows that they present very similar granular characteristics (particle size distribution, elongation, and packing density). Comparison of mortars made with LFA and saturated RFA shows that these two mortars present very close fresh state properties, showing that LFA is a good natural model aggregate for a rigorous comparison with RFA. 
Using the two previous aggregates, mechanical properties of mortars made with RFA in various saturation conditions are compared to those of mortars made with LFA of identical composition (same $\mathrm{W}_{\text {eff }} / \mathrm{C}$ ratio and same paste volume). Results show that the compressive strengths of mortars made with LFA are systematically larger than those of corresponding mortars made with RFA. The lower compressive strengths can be attributed to a lower quality of the bond between aggregates and cement matrix and to a larger air content in mortars made with RFA. Results also show that mortars containing saturated RFA present lower air contents than those with dry RFA, because of the air contained in non-filled voids of aggregates in the latter. However, the compressive strengths of mortars made with dry RFA are systematically larger than those of saturated RFA, because of a better adhesion between aggregates and cement matrix.

\section{Acknowledgment}

This research work has been carried out in the frame of the VALDEM project (convention $\mathrm{n}^{\circ} 1.1 .57$ of Interreg France-Wallonie-Vlaanderen 2014-2020), partly financed by the European Regional Development Funds and Wallonia.

\section{Conflict of interest}

The authors declare that they have no conflict of interest.

\section{References}

[1] R. PN, “Complete recycling of concrete,” 2012. [Online]. Available: http://www.pnrecybeton.fr/.

[2] FEREDECO, “Guide pour 1' utilisation des granulats recyclés en Wallonie," 2016.

[3] F. Rodrigues, M. T. Carvalho, L. Evangelista, and J. De Brito, "Physical-chemical and mineralogical characterization of fine aggregates from construction and demolition waste recycling plants," J. Clean. Prod., vol. 52, pp. 438-445, 2013.

[4] M. S. de Juan and P. A. Gutiérrez, "Study on the influence of attached mortar content on the properties of recycled concrete aggregate," Constr. Build. Mater., vol. 23, no. 2, pp. 872-877, 2009.

[5] F. Delobel, D. Bulteel, J. M. Mechling, A. Lecomte, M. Cyr, and S. Rémond, "Application of ASR tests to recycled concrete aggregates: Influence of water absorption," Constr. Build. Mater., vol. 124, pp. 714-721, 2016.

[6] Z. Zhao, S. Remond, D. Damidot, and W. Xu, "Influence of hardened cement paste content on the water absorption of fine recycled concrete aggregates," J. Sustain. Cem. Mater., vol. 2, no. 3-4, pp. 186-203, 2013. 
concrete aggregates on their properties," Eur. J. Environ. Civ. Eng., vol. 8189, no. March, p. 0, 2017. Z. J. Grdic, G. A. Toplicic-Curcic, I. M. Despotovic, and N. S. Ristic, "Properties of self-compacting concrete prepared with coarse recycled concrete aggregate," Constr. Build. Mater., vol. 24, no. 7, pp. 1129-1133, 2010.

[9] K. Kapoor, S. P. Singh, and B. Singh, "Durability of self-compacting concrete made with Recycled Concrete Aggregates and mineral admixtures," Constr. Build. Mater., vol. 128, pp. 67-76, 2016.

[10] L. Oksri-Nelfia, P. Mahieux, O. Amiri, P. Turcry, and J. Lux, "Reuse of recycled crushed concrete fines as mineral addition in cementitious materials," Mater. Struct., vol. 49, no. 8, pp. 3239-3251, 2016.

[11] C. Diliberto, A. Lecomte, J.-M. Mechling, L. Izoret, and A. Smith, "Valorisation of recycled concrete sands in cement raw meal for cement production," Mater. Struct., vol. 50, no. 2, p. 127, 2017.

[12] M. Braga, J. De Brito, and R. Veiga, "Incorporation of fine concrete aggregates in mortars," Constr. Build. Mater., vol. 36, pp. 960-968, 2012.

[13] C. Neno, J. de Brito, and R. Veiga, "Using fine recycled concrete aggregate for mortar production," Mater. Res., vol. 17, no. 1, pp. 168-177, 2014.

[14] I. Vegas, I. Azkarate, A. Juarrero, and M. Frías, "Design and performance of masonry mortars made with recycled concrete aggregates," Mater. Construcción, vol. 59, no. 295, pp. 5-18, 2009.

[15] D. Pedro, J. de Brito, and L. Evangelista, "Structural concrete with simultaneous incorporation of fine and coarse recycled concrete aggregates: Mechanical, durability and long-term properties," Constr. Build. Mater., vol. 154, pp. 294-309, 2017.

[16] D. Carro-Lopez, B. Gonzallez-Fonteboa, F. Martinez-Abella, I. Gonzallez-Taboada, J. De Brito, and F. Varela-Puga, "Proportioning, Microstructure and Fresh Properties of Self-compacting Concrete with Recycled Sand," Procedia Eng., vol. 171, pp. 645-657, 2017.

[17] S. Omary, E. Ghorbel, G. Wardeh and D. Nguyen, "Mix Design and Recycled Aggregates Effects on the Concrete's Properties," Int. J. Civ. Eng., 2017.

[18] C. C. Fan, R. Huang, H. Hwang, and S. J. Chao, "Properties of concrete incorporating fine recycled aggregates from crushed concrete wastes," Constr. Build. Mater., vol. 112, pp. 708-715, 2016.

[19] J. Hu, Z. Wang, and Y. Kim, "Feasibility study of using fine recycled concrete aggregate in producing self-consolidation concrete," J. Sustain. Cem. Mater., vol. 2, no. 1, pp. 20-34, 2013.

[20] B. M. Vinay Kumar, H. Ananthan, and K. V. A. Balaji, "Experimental studies on utilization of coarse and finer fractions of recycled concrete aggregates in self compacting concrete mixes," J. Build. Eng., vol. 9, no. December 2016, pp. 100-108, 2017.

[21] M. Omrane, S. Kenai, E. Kadri, and A. Ait-mokhtar, "Performance and durability of self compacting concrete using recycled concrete aggregates and natural pozzolan," Clean. Prod., vol. 165, pp. 415-430, 2017.

[22] S. C. Kou and C. S. Poon, "Properties of self-compacting concrete prepared with coarse and fine recycled concrete aggregates," Cem. Concr. Compos., vol. 31, no. 9, pp. 622-627, 2009.

[23] D. Carro-López, B. González-Fonteboa, J. De Brito, F. Martínez-Abella, I. González-Taboada, and P. Silva, "Study of the rheology of self-compacting concrete with fine recycled concrete aggregates," Constr. Build. Mater., vol. 96, pp. 491-501, 2015. 
Spheres," Trans. Soc. Rheol., vol. 3, pp. 137-152, 1959.

[25] F. De Larrard, "Structures granulaires et formulation des bétons," Etudes Rech. des Lab. des ponts chaussées, vol. OA 34, p. 414 p., 2000.

[26] A. Lecomte, "The Measurement of Real and Virtual Packing Density of Soft Grains," Mater. Struct., vol. 39, no. 1, pp. 63-80, 2007.

[27] K. H. Khayat and A. F. Omran, "Evaluation of SCC Formwork Pressure," Concr. InFocus, no. june, pp. 16-21, 2009.

[28] R. Cepuritis, S. Jacobsen, S. Smeplass, E. Mørtsell, B. J. Wigum, and S. Ng, "Influence of crushed aggregate fines with micro-proportioned particle size distributions on rheology of cement paste," Cem. Concr. Compos., vol. 80, pp. 64-79, 2017.

[29] H. Huan, L. Courard, E. PIrard, and Fr. MIchel, "SHAPE ANALYSIS OF FINE AGGREGATES USED FOR CONCRETE," Image Anal Stereol, pp. 159-166, 2016.

[30] E. 1097-6, "Tests for mechanical and physical properties of aggregates - Part 6: Determination of particle density and water absorption .," 2013.

[31] IFSTTAR. Test Methode No.78, "Tests on granulats in concrte: measurment of total water absorption of crushed sand," 2011.

[32] T. Le, S. Rémond, G. Le Saout, and E. Garcia-Diaz, "Fresh behavior of mortar based on recycled sand Influence of moisture condition,” Constr. Build. Mater., vol. 106, pp. 35-42, 2016.

[33] A. Bordy, A. Younsi, S. Aggoun, and B. Fiorio, "Cement substitution by a recycled cement paste fine: Role of the residual anhydrous clinker," Constr. Build. Mater., vol. 132, pp. 1-8, 2017.

[34] I. Mehdipour and K. H. Khayat, "Understanding the role of particle packing characteristics in rheophysical properties of cementitious suspensions: A literature review," Constr. Build. Mater., vol. 161, no. December 2017, pp. 340-353, 2018.

[35] A. Schwartzentruber and C. Catherine, "La mdthode du mortier de bdton quivalent ( MBE ) - Un nouvel outil d'aide à la formulation des bdtons adjuvantds," Mater. Struct., vol. 33, no. October, pp. 475-482, 2000.

[36] N. Roussel and P. Coussot, “'Fifty-cent rheometer” for yield stress measurements: From slump to spreading flow," J. Rheol. (N. Y. N. Y)., vol. 49, no. 3, pp. 705-718, 2005.

[37] M. Fourmentin et al., "NMR observation of water transfer between a cement paste and a porous medium," Cem. Concr. Res., vol. 95, pp. 56-64, 2017.

[38] V. H. Nguyen, S. Remond, and J. L. Gallias, "Influence of cement grouts composition on the rheological behaviour," Cem. Concr. Res., vol. 41, no. 3, pp. 292-300, 2011.

[39] H. Maimouni, S. Remond, F. Huchet, P. Richard, and V. Thiery, "Quantitative assessment of the saturation degree of model fine recycled concrete aggregates immersed in a filler or cement paste," Constr. Build. Mater., vol. 175, pp. 496-507, 2018.

[40] Z. Zhao, S. Remond, D. Damidot, and W. Xu, "Influence of fine recycled concrete aggregates on the properties of mortars," Constr. Build. Mater., vol. 81, pp. 179-186, 2015.

[41] T. Le, G. Le Saout, E. Garcia-Diaz, D. Betrancourt, and S. Rémond, "Hardened behavior of mortar based on recycled aggregate: Influence of saturation state at macro- and microscopic scales," Constr. Build. Mater., vol. 141, pp. 479-490, 2017. 
633 [42] A. de Larrard, F. Belloc, "The influence of Aggregate on the compressive Streght of Normal-and hight-

2 3635

4

5

6

7

8

9

10

11

12

13

14

15

16

17

18

19

20

21

22

23

24

25

26

27

28

29

30

31

32

33

34

35

36

37

38

39

40

41

42

43

44

45

46

47

48

49

50

51

52

53

54

55

56

57

58

59

60

61

62

63

64

65

Stregth Concrete," ACI Mater. J., vol. 99, no. 5, 1997. 